\title{
Antioxidant potential and cytotoxicity of Randia dumetorum Lam. leaf extract
}

\author{
Abdullah-Al-Ragib ${ }^{1}$, Md. Tanvir Hossain ${ }^{1}$, Javed Hossain ${ }^{2}$ and Md. Jakaria ${ }^{2,3^{*}}$ \\ ${ }^{1}$ Department of Applied Chemistry and Chemical Engineering, Noakhali Science and Technology University, Sonapur, \\ Noakhali-3814, Bangladesh. \\ ${ }^{2}$ Department of Pharmacy, International Islamic University Chittagong, Chittagong-4314, Bangladesh. \\ ${ }^{3}$ Department of Pharmacy, Southern University Bangladesh, Chittagong-4000, Bangladesh.
}

Received 18 October, 2016; Accepted 6 December, 2016

\begin{abstract}
The aim of the current study was to explore the antioxidant potential and cytotoxicity of different 'fractions from the leaf extract of Randia dumetorum. Proximate analysis and phytochemical screening were done with standard protocol. The antioxidant activity was evaluated by using reducing power assay, total antioxidant capacity determination, determination of total phenolic content, determination of total flavonoid content and reduction of ferric ions by ortho-phenanthroline color method. In the antioxidant studies, ascorbic acid, gallic acid and butylated hydroxy toluene (BHT) were used as standard antioxidant compound. The brine shrimp lethality test was used to examine cytotoxicity. In the proximate analysis, moisture content, total ash value, acid insoluble ash and water-soluble ash value were found in the leaf of $R$. dumetorum. Concerning the phytochemical screening, there was the presence of glycosides, flavonoids, reducing sugars, saponins, phenolic compounds, tannins on different fractions, but the absence of gums and mucilage, alkaloid, protein, and amino acid. The results show that all the extracts of $\boldsymbol{R}$. dumetorum leaf possess significant antioxidant activity. 'The methanol and water extracts of the leaves showed significant cytotoxic activity as compared to dimethyl sulfoxide (DMSO) $\left(\mathrm{LC}_{50} 1.07 \mu \mathrm{g} / \mathrm{ml}\right)$. These findings suggest that $R$. dumetorum leaves might be a good antioxidants source and possess mild cytotoxic effect.
\end{abstract}

Key words: Randia dumetorum, proximate analysis, phytochemical screening, antioxidant, lethality bioassay.

\section{INTRODUCTION}

Reactive oxygen species (ROS) or free radicals are harmful products or intermediates that may be generated during the processes of biological combustion (Sharma and Vig, 2013; Zaman et al., 2016). The imbalance between oxidants and antioxidants are called oxidative stress, because of the damage in all kinds of biomolecules such as protein, nucleic acid, DNA and RNA (Sharma and Vig, 2013). An excess level of free radicals in living beings causes numerous disorders and diseases including cardiovascular diseases, cancer, asthma, liver diseases, aging, muscular degeneration, neurodegeneration and other inflammatory diseases

${ }^{*}$ Corresponding author. E-mail: pharmajakaria@rocketmail.com.

Author(s) agree that this article remain permanently open access under the terms of the Creative Commons Attribution License 4.0 International License 
(Sharma and Vig, 2013; Saeed et al., 2012; Sen et al., 2010; Kanwar et al., 2009; Chiavaroli et al., 2011).

Antioxidants are known as a reducing agent, free radical scavenger, singlet oxygen molecule quenchers and antioxidative enzyme activators to suppress the damage induced by free radicals in biological system (Sharma and Vig, 2013). The imbalance between ROS and the inherent antioxidant capacity of the body, led to the use of dietary and/or medicinal supplements particularly during the disease attack. Henceforth, the balance between reactive species or free radicals and antioxidants is supposed to be an important concept for maintaining a good biological system. It has been reported that the evidence has brought the attention of scientists to an appreciation of antioxidants for prevention and treatment of diseases and maintenance of human health. Moreover, antioxidants present in plant products support the cellular defense system stimulation and biological system against oxidative damage.

Randia dumetorum Lam. (RD) is an important medicinal plant and it is a big thorny shrub. It belongs to the Rubiaceae family (Jangwan and Singh, 2014; Dharmishtha et al., 2009). This plant is commonly obtainable all over the India and African subcontinent up to 4000 feet elevation. It has been considered that different phytochemicals including iridoid-10methylixoside, mannitol, triterpenoid glycosides, coumarin glycosides, randianin and saponins named as dumentoronin A, B, C, D, E, F, etc., are available in the RD. In ayurvedic system of medicines, RD has been used because of its potentials for rasa, virya, guna, vipaka, etc. (Patel et al., 2011). Many practitioners believed, the pulp of fruit also have anthelmintic properties and also indicated as an abortifacient. RD fruits are believed to be tonic, demulcent, diuretic and restorative and the drug is claimed as a medical cure for various ailments, such as piles, antidysenteric agent, asthma, jaundice, diarrhea, emetic, and gonorrhea (Satpute et al., 2014). Literature revealed that RD has several pharmacological activities as cytotoxic, immunomodulatory, antifertility, analgesic, antiinflammatory, antiallergic, antibacterial, insecticidal, and anthalmetics activities (Patel et al., 2011; Satpute et al., 2014). In addition, the methanol extract from the RD leaf and bark shows antioxidant and hepatoprotective activities (Satpute et al., 2014; Kandimalla et al., 2016).

To date, the antioxidant potential and cytotoxicity of different fraction from the leaves of $R$. dumetorum Lam. remain uninvestigated. Therefore, the present study was to explore the antioxidant potentiality and cytotoxicity of fractions from the $R$. dumetorum leaves.

\section{MATERIALS AND METHODS}

Plant

Concerning the collection, the leaves of $R$. dumetorum were collected from the Chatkil, Noakhali, Bangladesh on 5th March,
2015. The leaves were washed properly and air dried for several days. The dried leaves were then oven dried for $24 \mathrm{~h}$ at a considerably low temperature not exceeding $50^{\circ} \mathrm{C}$. The oven dried leaves were then ground into coarse powder using high capacity grinding machine and were used for different investigation.

\section{Proximate analysis}

Regarding the proximate analysis, the moisture content, total ash value, acid insoluble ash value and water-soluble ash value of a substance were determined in the samples.

\section{Preparation of plant extracts}

The dried leaf powder of $R$. dumetorum (about $190 \mathrm{~g}$ ) was extracted with $\mathrm{n}$-hexane $(600 \mathrm{ml})$ by using Soxhlet apparatus for $8 \mathrm{~h}$ at 60 to $80^{\circ} \mathrm{C}$. After n-hexane extraction, the residual dried marc was extracted with chloroform, methanol and water to get chloroform, methanol and water extracts. In the case of aqueous extract preparation, the dried marc was macerated for 3 days with distilled water and the residue was removed by filtration and the filtrate was concentrated to obtain aqueous extract. The extracts of different solvents obtained were concentrated by recovery of the solvent in a rotary evaporator and evaporating them to dryness at low temperature. These concentrated extracts were then weighed and stored for the investigations.

\section{Phytochemical screening}

The extracts were exposed to initial phytochemical testing. Small quantity of freshly prepared $n$-hexane, chloroform, methanol and aqueous extracts of $R$. dumetorum were subjected to preliminary quantitative phytochemical investigation for detection of phytochemicals such as alkaloids, flavonoids, reducing sugars, saponins, phenolic compounds, proteins and amino acids, tannins, gums and mucilage using the standard methods (Mujeeb et al., 2014; Todkar et al., 2010; Thamaraiselvi et al., 2012; Auwal et al., 2014; Mandal et al., 2013; Chinedu et al., 2015; Sumbul et al., 2012).

\section{Antioxidant activity}

The antioxidant activity of different extracts of leaf of $R$. dumetorum was evaluated by the following methods: reducing power assay, total antioxidant capacity determination, determination of total phenolic content, total flavonoid content determination and reduction of ferric ions by ortho-phenanthroline color method.

\section{Reducing power assay}

The $\mathrm{Fe}^{3+}$-reducing power of the extract was investigated by following the method with a slight modification described by Oyaizu (1986). $2 \mathrm{ml}$ methanol and $2 \mathrm{ml}$ extract of each solvent of different concentrations $(31.25,62.50,125,250$, and $500 \mu \mathrm{g} / \mathrm{ml})$ of the extract were mixed with $0.5 \mathrm{ml}$ phosphate buffer $(0.2 \mathrm{M}, \mathrm{pH} 6.6)$ and $0.5 \mathrm{ml}$ potassium hexacyanoferrate (1\%), followed by incubation at $50^{\circ} \mathrm{C}$ in a water bath for $20 \mathrm{~min}$. For subsequent incubation, $0.5 \mathrm{ml}$ of TCA (10\%) was added to terminate the reaction and centrifuged at $3000 \mathrm{rpm}$ for $10 \mathrm{~min}$. $1 \mathrm{ml}$ solution from the upper portion of the solution was mixed with $1 \mathrm{ml}$ distilled water and $0.2 \mathrm{ml} \mathrm{FeCl}_{3}$ solution $(0.1 \%)$ and the absorbance was measured at $700 \mathrm{~nm}$ against an appropriate blank solution. At several concentrations, ascorbic acid was used as standard. 
Increased absorbance of the reaction mixture designated increased reducing power.

\section{Total antioxidant capacity}

Extracts total antioxidant capacity was assessed by following the method described by Prieto et al. (1999) with slight modification. An aliquot of $0.5 \mathrm{ml}$ of samples solution was combined with $4.5 \mathrm{ml}$ of reagent solution $(0.6 \mathrm{M}$ sulfuric acid, $28 \mathrm{mM}$ sodium phosphate, and $4 \mathrm{mM}$ ammonium molybdate). Concerning the blank, $0.5 \mathrm{ml}$ of $45 \%$ ethanol was used in place of sample. The tubes were incubated in a boiling water bath at $95^{\circ} \mathrm{C}$ for $90 \mathrm{~min}$. At room temperature, after cooling the sample, the aqueous solution absorbance of each sample was determined at $695 \mathrm{~nm}$ against blank. The total antioxidant activity was shown as the absorbance of the sample at $695 \mathrm{~nm}$. The higher absorbance value specified higher antioxidant activity (Prasad et al., 2009).

\section{Total phenolic content}

Folin-Ciocalteu method was used to determine the total phenolic content of all the extracts (Harborne, 1973). Polyphenols containing samples are reduced by the Folin-Ciocalteu reagent, thereby producing blue colored complex. From a gallic acid calibration curve, the phenolic concentration of extracts was estimated. To prepare a calibration curve, $0.5 \mathrm{ml}$ aliquots of $3.9,7.82,15.63$, $31.25,62.5,125,250$ and $500 \mu \mathrm{g} / \mathrm{ml}$ gallic acid solutions were mixed with $2.5 \mathrm{ml}$ Folin-Ciocalteu reagent (diluted ten-fold) and 2.5 $\mathrm{ml}(75 \mathrm{~g} / \mathrm{L})$ sodium carbonate. After incubation at $25^{\circ} \mathrm{C}$ for $30 \mathrm{~min}$, the quantative phenolic estimation was performed at $765 \mathrm{~nm}$ against reagent blank. The calibration curve was constructed by putting the value of absorbance vs. concentration. A similar procedure was adopted for the extracts as described earlier in the preparation of calibration curve. All determinations were performed in triplicate. Total phenolic content was expressed as milligrams of gallic acid equivalent (GAE) per $g$ of the extract.

\section{Determination of total flavonoids}

The flavonoids content was determined by aluminium trichloride method using quercetin as a reference compound (Chang et al., 2002). This method is based on the formation of a complex flavonoid-aluminum having the absorptivity maximum at $415 \mathrm{~nm}$, after being left to react at room temperature for $30 \mathrm{~min}$. Briefly, 0.5 $\mathrm{ml}$ of each extract $(1: 10 \mathrm{~g} / \mathrm{ml})$ in ethanol was separately mixed with $1.5 \mathrm{ml}$ of ethanol, $0.1 \mathrm{ml}$ of $10 \%$ aluminium chloride, $0.1 \mathrm{ml}$ of $1 \mathrm{M}$ potassium acetate and distilled water $(2.8 \mathrm{ml})$. The calibration curve was arranged by preparing quercetin solutions at different concentrations from 0 to $1.00 \mathrm{mg} / \mathrm{ml}$ in ethanol.

\section{Reduction of ferric ions by ortho-phenanthroline color method}

A reaction mixture containing $0.5 \mathrm{ml}$ o-phenanthroline $(5 \mathrm{mg}$ in 10 $\mathrm{ml}$ methanol), $2 \mathrm{ml}$ ferric chloride $0.2 \mu \mathrm{M}$ (3.24 mg in $100 \mathrm{ml}$ distilled water) and $1 \mathrm{ml}$ of numerous concentrations of the extracts was incubated at ambient temperature for $10 \mathrm{~min}$, then the absorbance was determined at $510 \mathrm{~nm}$. In this investigation, ascorbic acid and gallic acid were used as reference standards (Hukkeri and Mruthunjaya, 2008).

\section{Cytotoxicity}

The cytotoxicity was conducted by using brine shrimp lethality examination. Concerning the test organism, Artemia salina leach (brine shrimp eggs) collected from pet shops was used. The brine shrimp eggs were placed in $1 \mathrm{~L}$ of simulated sea water, aerated for $48 \mathrm{~h}$ at $38^{\circ} \mathrm{C}$ to hatch and become nauplii. After $24 \mathrm{~h}$, ten brine shrimp nauplii were placed in a small container filled with sea water. $R$. dumetorum extract serially diluted with simulated sea water were then added to the container. The lethality of brine shrimp was observed after $24 \mathrm{~h}$ of treatment was given. In the present study, positive control group (vincristine sulphate) was not used and the results obtained are only due to the activity of the test agent such as DMSO as the negative control. Following the procedure of Meyer et al. (1982), the lethality of the crude methanol and water extract was determined but $n$-hexane and chloroform extract was not determined, because of the results of the chemical tests. At different concentrations, each test samples exhibited dissimilar mortality rates; plotting of log of concentration versus percent mortality for all test samples showed an approximate linear correlation. The median lethal concentration ( $\mathrm{LC}_{50}$, the concentration at which $50 \%$ mortality of brine shrimp nauplii occurred) was determined for the samples by using the graphs. Probity analysis was used to determine lethal concentration $\left(\mathrm{LC}_{50}\right)$ of $R$. dumetorum extract on nauplii.

\section{RESULTS}

\section{Proximate analysis}

Proximate analysis of a substance constitutes different classes of nutrients present in the samples such as moisture, ash, carbohydrates, protein, fat and crude fibre. $R$. dumetorum was subjected to evaluate its moisture content, total ash value, acid insoluble ash and watersoluble ash (Figure 1).

\section{Phytochemical screening}

In the pharmaceutical screening, it is observed that reducing sugar, flavonoid, phenolic compound and tannins were present in the methanol extract of $R$. dumetorum in addition, except methanol extract saponin was present in all the extracts. On the other hand, no extracts of $R$. dumetorum contains alkaloids, protein, amino acid and gums (Table 1).

\section{Antioxidant activity}

\section{Reducing power assay}

Figure 2 elucidates the dose response curves for the reducing powers of all extracts $(31.25$ to $500 \mu \mathrm{g} / \mathrm{ml})$ from $R$. dumetorum. It shows that the $\mathrm{n}$-hexane and chloroform fraction reduced the $\mathrm{Fe}^{3+}$ to ferrous ions $\left(\mathrm{Fe}^{2+}\right)$ more effectively (2.057 and 2.382) as compared to the methanol and water fraction (1.921 and 1.124), respectively at $500 \mu \mathrm{g} / \mathrm{ml}$ concentration. Ascorbic acid was used as standard antioxidant for comparison.

\section{Total antioxidant capacity determination}

Total antioxidant activity (TAC) of the extracts as shown 


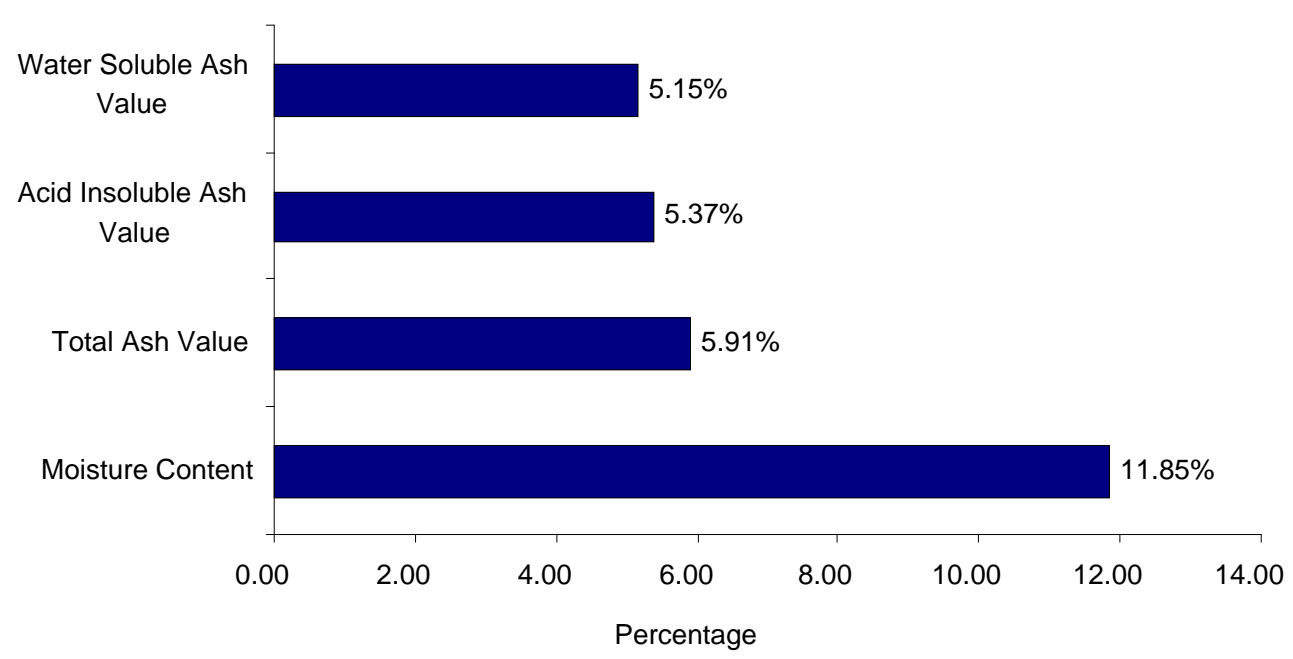

Figure 1. Result of proximate analysis of $R$. dumetorum.

Table 1. Phytochemical compounds in the different fractions of $R$. dumetorum.

\begin{tabular}{llcccc}
\hline \multirow{2}{*}{ Plant name } & Phytochemical composition & \multicolumn{4}{c}{ Results of different extracts } \\
\cline { 2 - 6 } & Alkaloid & n-Hexane & Chloroform & Methanol & Water \\
\hline & Reducing sugar & - & - & - & - \\
& Glycoside & - & - & ++ & + \\
& Flavonoid & - & - & - & + \\
\multirow{5}{*}{ dumetorum } & - & - & + & + \\
& Saponin & + & + & - & + \\
& Phenolic compound & - & - & + & + \\
& Tannin & - & - & - & - \\
\hline
\end{tabular}

+ = Present; - = Absent; ++ = significantly present.

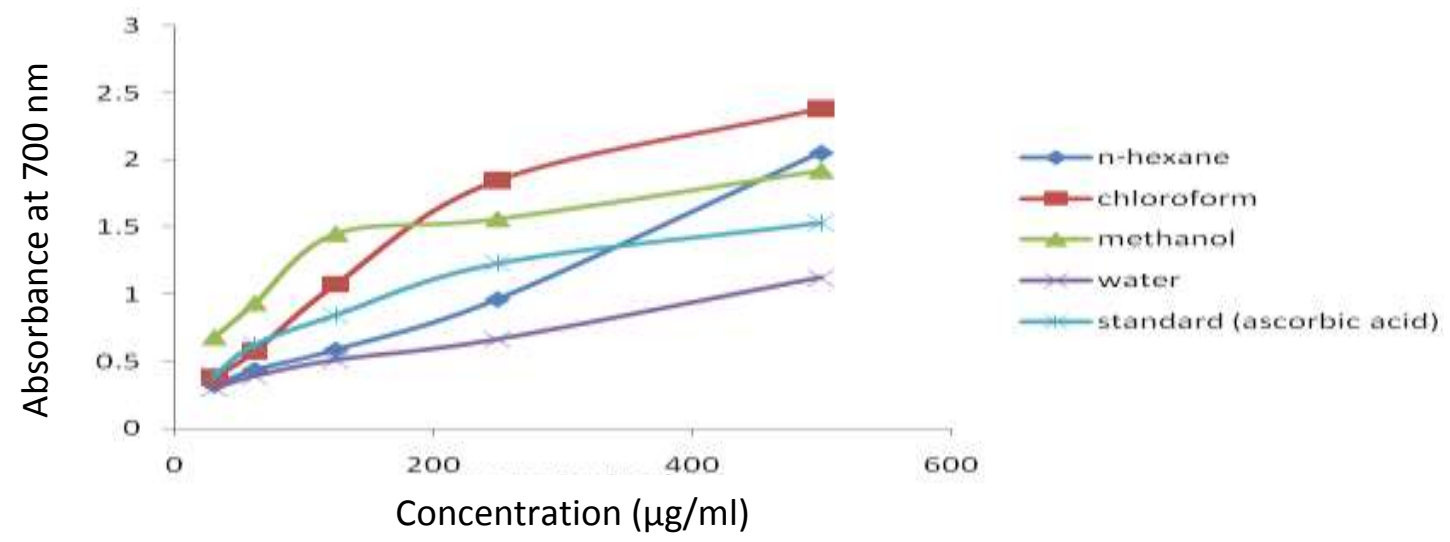

Figure 2. Comparative analysis of different extracts of $R$. dumetorum with standard (ascorbic acid) antioxidant for reducing power assay.

in Figure 3 was based on the reduction of $\mathrm{Mo}(\mathrm{VI})$ to $\mathrm{Mo}$ (V) by the extract and subsequent formation of green
phosphate/Mo (V) complex with a maximum absorbance at $695 \mathrm{~nm}$. The results specify a concentration dependent 


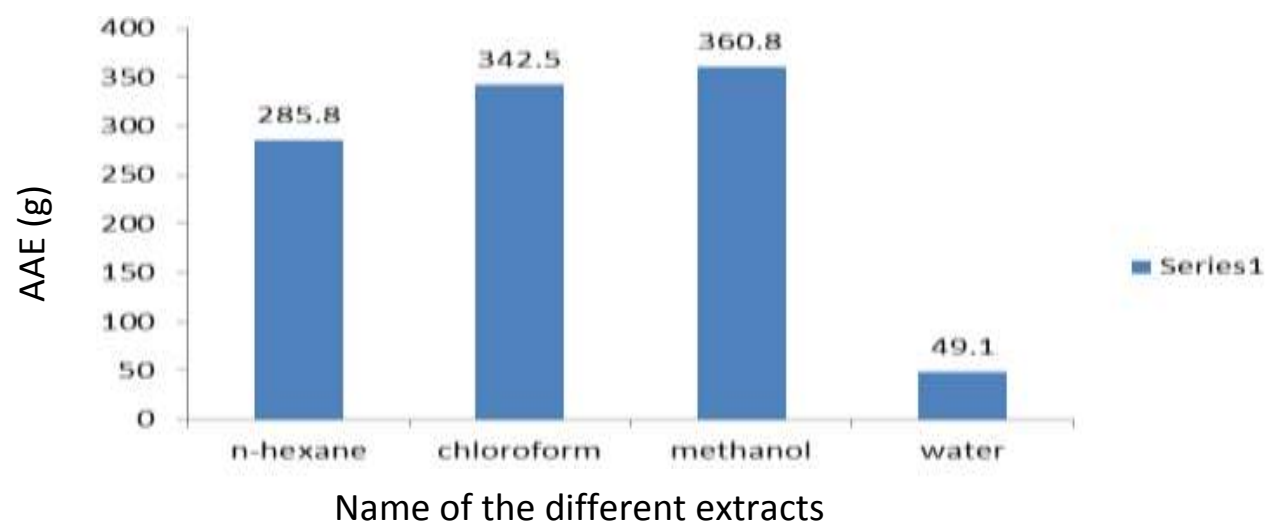

Figure 3. Total antioxidant capacity of different solvent extracts for $500 \mathrm{ppm}$ at $695 \mathrm{~nm}$ of $R$. dumetorum.

Table 2. Total phenolic content and total flavonoid content of $R$. dumetorum.

\begin{tabular}{lcc}
\hline Plant extracts & Total phenolics (mg gallic acid equivalent/g) & Total flavonoid (mg quercetin equivalent/g) \\
\hline n-Hexane & - & - \\
Chloroform fraction & - & - \\
Methanol fraction & 131.40 & 40.71 \\
Water & 55.00 & - \\
\hline
\end{tabular}

total antioxidant capacity. The antioxidant activities of the fractions were compared with the standard antioxidant ascorbic acid. The total antioxidant capacity of several solvent fractions of $R$. dumetorum were found to decrease in this order: methanol (360.8 AAE/g) > chloroform (342.5 AAE/g) > n-hexane (285.8 AAE/g) > water (49.1 AAE/g).

\section{Total phenolic content and total flavonoid content}

Total phenolic content of the different fractions of $R$. dumetorum was solvent dependent and expressed as milligrams of gallic acid equivalents (GAE). The methanol extracts (131.4 GAE/g) show higher concentration of phenolic content than water extracts (55 GAE/g). The method of aluminium chloride colorimetric is extensively used to detect the total flavonoid. Here, $\mathrm{Al}^{3+}$ forms color that give a great absorbance at $415 \mathrm{~nm}$. Flavonoid was found in methanol only in group test results. Methanol extracts of $R$. dumetorum was found to contain the amount of flavonoid content (40.71 mg quercetin equivalent/g of extract) (Table 2).

\section{Reduction of ferric ions by ortho-phenanthroline color method}

Figure 4 shows the comparative analysis of different extracts of leaf of $R$. dumetorum. In this figure, the value of $n$-hexane and chloroform extract (1.023 and 0.543$)$ is significantly higher than the standard antioxidant gallic acid and ascorbic acid (0.324 and 0.167$)$, respectively tested at $500 \mu \mathrm{g} / \mathrm{ml}$.

\section{Cytotoxicity}

In cytotoxicity study, $\mathrm{LC}_{50}$ values of crude methanol and water extract was found to be 0.94 and $0.23 \mu \mathrm{g} / \mathrm{ml}$, respectively. The negative control DMSO showed $\mathrm{LC}_{50}$ at a concentration of $1.07 \mu \mathrm{g} / \mathrm{ml}$ (Table 3 ).

\section{DISCUSSION}

As an alternative to clinical therapy, medicine from herbal sources has received enormous attention for different diseases and the demand for these therapies has presently increased speedily. The raise in the number of users as compared to the shortage of scientific evidences on the medicinal plants safety, have raised concerns about the toxicity and detrimental effects of these medications (Saad et al., 2006; Sahgal et al., 2010; Jakaria et al., 2015). Principally, plants are the main source of secondary metabolites apart from their food value, and their plant secondary metabolites prevent diseases in the form of antioxidant, antiviral, antibacterial and anticancer compounds (Makkar et al., 2007). In this study, several in vitro tests were used to investigate 


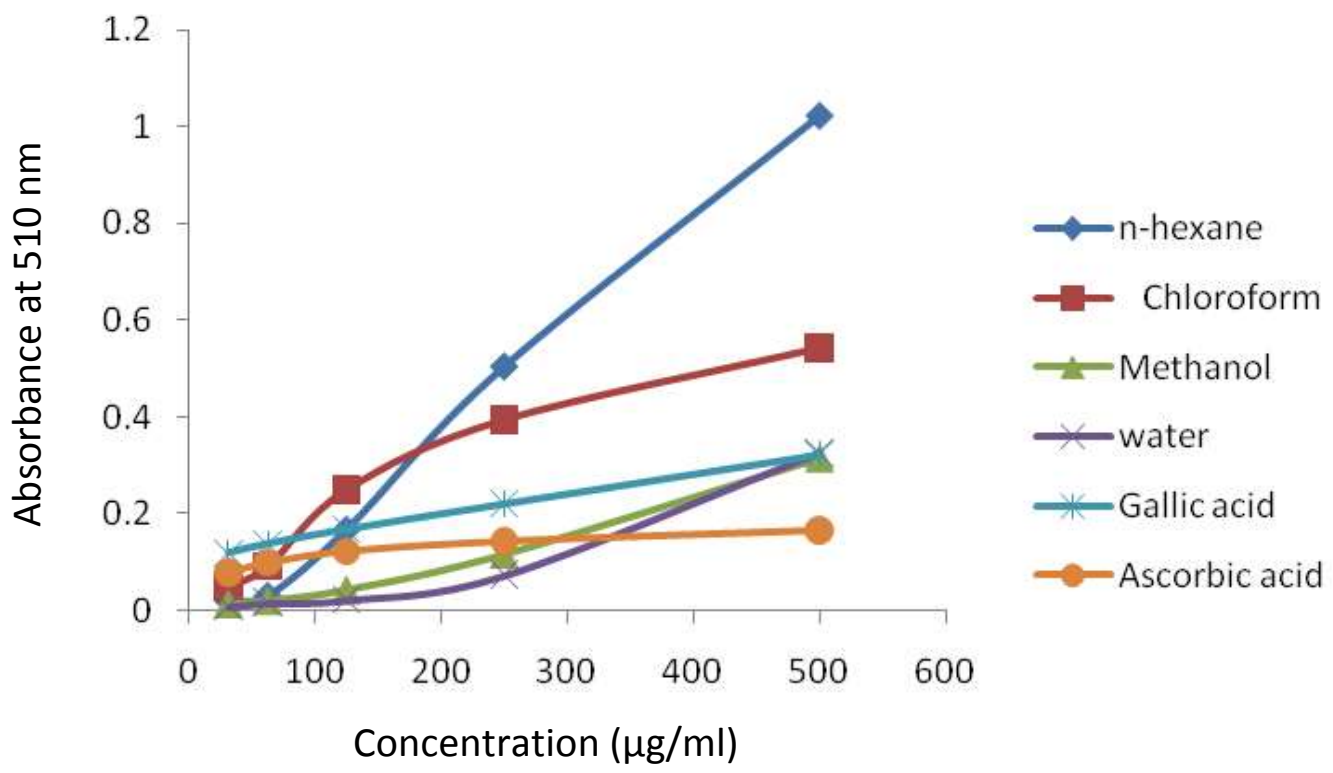

Figure 4. Comparative analysis of different extracts of $R$. dumetorum with standard antioxidants for Reduction of Ferric Ions by Ortho-phenanthroline Color method.

Table 3. Effect of extract of $R$. dumetorum on brine shrimp nauplii.

\begin{tabular}{lc}
\hline Sample/Extract & LC $_{50}(\mu \mathrm{g} / \mathrm{ml})$ \\
\hline DMSO (negative control) & 1.07 \\
n-Hexane & - \\
Chloroform & - \\
Methanol extract & 0.94 \\
Water extract & 0.23 \\
\hline
\end{tabular}

antioxidant activity and brine shrimp lethality assay was used to investigate cytotoxic activity.

It has been familiar that free radicals are identified to play a certain role in an extensive variety of pathological manifestations. Antioxidants fight against free radicals and defend the body from several diseases. They show their action either by scavenging the reactive oxygen species or protecting the antioxidant defense mechanisms (Umamaheswari and Chatterjee, 2008).

In the assay of reducing power, depending on the reducing power of the test specimen, the yellow color of the test solution changes to green. The reductants presence in the solution causes the reduction of the $\mathrm{Fe}^{3+} /$ ferricyanide complex to the ferrous form. Therefore, $\mathrm{Fe}^{2+}$ can be checked by absorbance measurement at 700 $\mathrm{nm}$. According to the previous reports, the reducing properties have been shown to exert antioxidant activity by donating of hydrogen atom to break the free radical chain (Gordon, 1990). At $700 \mathrm{~nm}$, the increasing absorbance indicates an increase in reducing ability. In the fractions of $R$. dumetorum, the presence of the antioxidants caused their reduction of $\mathrm{Fe}^{3+} /$ ferricyanide complex to the ferrous form, and thus demonstrated the reducing power.

The antioxidant capacity of the fractions was measured spectrophotometrically through phosphomolybdenum method, based on the reduction of Mo $(\mathrm{VI})$ to Mo $(\mathrm{V})$ by the test sample and the consequent formation of green phosphate/Mo (V) compounds. Recent studies have shown that numerous flavonoid and related polyphenols contribute significantly to the phosphomolybdate scavenging activity of medicinal plants (Sharififar et al., 2009; Khan et al., 2012). Regarding the result of total antioxidant activity, the methanol and chloroform fractions of $R$. dumetorum contain antioxidant compounds as equivalents of ascorbic acid to efficiently decrease the oxidant in the reaction matrix.

Phenolic compounds are considered secondary metabolites and these phytochemical compounds derived from phenylalanine and tyrosine occur ubiquitously in plants and are diversified (Naczk and Shahidi, 2004). Plants phenolic compounds are also very important because their hydroxyl groups confer scavenging capability. In the preliminary phytochemical investigation, 
only methanol and water extract showed the presence of phenol. That is why, only methanol and water extracts are tested for total phenolic content. The other two extracts ( $n$-hexane and chloroform) did not show the presence of phenol in the preliminary phytochemical investigation. Flavonoids are naturally occurring in plants and are believed to have positive effects on human health. Regarding the studies on flavonoidic derivatives, they shown a wide range of antibacterial, antiviral, antiinflammatory, anti-allergic and anticancer activities ( $\mathrm{Di}$ Carlo et al., 1999; Montoro et al., 2005).

Flavonoids have been shown to be extremely effective scavengers of most oxidizing molecules, including singlet oxygen and various free radicals (Bravo, 1998) implicated in several diseases. In methanol extract, total phenolic content is significantly higher than total flavonoid content. To estimate antioxidant activity, the ferric ion reduction is expansively used. Gallic and ascorbic acids have been used as standard antioxidant in this method. $\mathrm{Fe}^{2+}$ reacts rapidly with 1, 10-o-phenanthroline and forms a red colored complex which is exceptionally stable. The synthesized compounds react with $\mathrm{Fe}^{3+}$ to reduce and change it to $\mathrm{Fe}^{2+}$. The degree of coloration designates the reduction potential of the compounds. The methanol and water extract $(0.314$ and 0.326$)$ also contributed fairly outstanding antioxidant activity at $500 \mu \mathrm{g} / \mathrm{ml}$. So, nhexane and chloroform showed appreciable antioxidant activity than methanol and water extract and also standard antioxidants.

As an initial indicator of in vivo antitumour activity, the in vitro cytotoxicity of the plant extracts were usually tested. Though, an extensive range of phyto compounds are capable of exhibiting nonspecific cytotoxicity, plant extracts with significant cytotoxic activity should be further examined using animal models to confirm antitumor activity, and/or a battery of various cell lines to detect specific cytotoxicity. This step is essential to eliminate cytotoxic compounds with little value for additional investigation as anticancer agents (Ali et al., 1996). From the results of the brine shrimp lethality bioassay, it can be well predicted that both the methanol and water extracts possess less cytotoxic potency. DMSO showed the highest potency than both methanol and water extracts. Besides, cytotoxic potency of methanol extract is higher than water extract of leaves of $R$. dumetorum. When compared with negative control DMSO, it shows that cytotoxicity exhibited by methanol and water extract might have low cytotoxic and anti-tumor activity.

\section{Conclusion}

Conclusively, the different leaf extracts of $R$. dumetorum might be potential as antioxidant substances and cytotoxic compounds. Further studies are needed to isolate and reveal the active compounds contained in the different solvent extracts of $R$. dumetorum responsible for these activities and to establish the mechanism of action.

\section{CONFLICT OF INTERESTS}

The authors have not declared any conflict of interests.

\section{ACKNOWLEDGEMENT}

The authors are grateful to the Department of Applied Chemistry and Chemical Engineering, Noakhali Science and Technology University, for providing the laboratory facilities for the research work.

\section{REFERENCES}

Auwal MS, Saka S, Mairiga IA, Sanda KA, Shuaibu A, Ibrahim A (2014). Preliminary phytochemical and elemental analysis of aqueous and fractionated pod extracts of Acacia nilotica (Thorn mimosa). Vet. Res. For. 5(2):95-100.

Ali AM, Mackeen MM, Saleh H, Ei-Sharkawy, Hamid JA, Ismail NH, Ahmadi FBH, Lajis NH (1996). Antiviral and cytotoxic activities of some plants used in Malaysian indigenous medicine. Pertanika $\mathrm{J}$. Trop. Agric. Sci. 19(2/3):129-136.

Bravo L (1998). Polyphenols: chemistry, dietary sources, metabolism and nutritional significance. Nutr. Rev. 56:317-333.

Chiavaroli V, Giannini C, De Marco S, Chiarelli F, Mohn A (2011). Unbalanced oxidant-antioxidant status and its effects in pediatric diseases. Redox Rep. 16:101-107.

Chinedu E, David A, Ameh SF (2015). Phytochemical evaluation of the ethanolic extracts of some Nigerian herbal plants. Drug Dev. Ther. 6(1):11-14.

Chang C, Yang M, Wen H, Chern J (2002). Estimation of total flavonoid content in Propolis by two comple mentary colorimetric methods. J. Food Drug Anal. 10(3):178-182.

Dharmishtha AM, Mishra SH, Falguni PG (2009). Antioxidant Studies of Methanolic Extract of Randia dumetorum lam. Pharmacologyonline 1:22-34.

Di Carlo G, Mascolo N, Izzo AA, Capasso F (1999). Flavonoids: old and new aspects of a class of natural therapeutic drugs. Life Sci. 65:337353.

Gordon MH (1990). The mechanism of antioxidant action in vitro. In Food antioxidants. Edited by Hudson BJ. London: Elsevier Applied Science Series. pp. 1-18.

Harborne JB (1973). Phytochemical methods. London: Chapman and Hall. pp. 49-188.

Hukkeri VI, Mruthunjaya K (2008). In vitro antioxidant and free radical scavenging potential of Parkinsonia aculeate Linn, Pharmacog. Mag. 4:42-48.

Jangwan JS, Singh R (2014). In vitro cytotoxic activity of triterpene isolated from bark of Randia Dumetorum Lamk. J. Curr. Chem. Pharm. Sci. 4(1):1-9.

Jakaria M, Parvez M, Zaman R, Arifujjaman, Hasan MI, Sayeed MA, Ali $\mathrm{MH}$ (2015). Investigations of Analgesic Activity of the Methanol Extract of Haldina cordifolia (Roxb.) Bark by using in vivo Anim. Model Stud. Res. J. Bot. 10:98-103.

Kanwar JR, Kanwar RK, Burrow H, Baratchi S (2009). Recent advances on the roles of $\mathrm{NO}$ in cancer and chronic inflammatory disorders. Curr. Med. Chem. 16:2373-2394.

Kandimalla R, Kalita S, Saikia B, Choudhury B, Singh YP, Kalita K, Dash S and Kotoky J (2016). Antioxidant and Hepatoprotective Potentiality of Randia dumetorum Lam. Leaf and Bark via Inhibition of Oxidative Stress and Inflammatory Cytokines. Front. Pharmacol. 7:205.

Khan RA, Khan MR, Sahreen S (2012). Assessment of flavonoids contents and in vitro antioxidant activity of Launaea procumbens. 
Chem. Central. J. 6:43.

Mujeeb F, Bajpai P, Pathak N (2014). Phytochemical Evaluation, Antimicrobial Activity, and Determination of Bioactive Components from Leaves of Aegle marmelos. BioMed. Res. Intl. ID 497606.

Mandal S, Patra A, Samanta A, Roy S, Mandal A, Mahapatra TD, Pradhan S, Das K, Nandi DK (2013). Analysis of phytochemical profile of Terminalia arjuna bark extract with antioxidative and antimicrobial properties. Asian Pac. J. Trop. Biomed. 3(12):960-966.

Meyer BN, Ferrigni NR, Putnam JE, Jacobsen LB, Nichols DJ, McLaughlin JL (1982). Brine shrimp: a convenient general bioassay for active plant constituents. Planta Med. 45(05):31-34.

Makkar HPS, Siddhuraju P, Becker K (2007). Plant Secondary Metabolites, Humana Press, Totowa, NJ, USA.

Montoro P, Braca A, Pizza C, De Tommasi N (2005). Structureantioxidant activity relationships of flavonoids isolated from different plant species. Food Chem. 92:349-355.

Naczk M, Shahidi $F$ (2004). Extraction and analysis of phenolics in food. J. Chromatogr. A. 1054:95-111.

Oyaizu M (1986). Studies on product of browning reaction prepared from glucose amine. Jap. J. Nutr. 44:307-315.

Patel RG, Pathak NL, Rathod JD, Patel LB, Bhatt NM (2011). Phytopharmacological properties of Randia dumetorumasa potential medicinal tree: an overview. J. Appl. Pharm. Sci. 10:24-26.

Patil MJ, Bafna AR, Bodas K, Shafi S (2014). In vitro antioxidant activity of fruits of Randia dumetorum Lamk.

Prieto P, Pineda M, Aguilar M (1999). Spectrophotometric quantitation of antioxidant capacity through the formation of a phosphomolybdenum complex: Specific application to the determination of vitamin E. Anal. Biochem. 269:337-341.

Prasad KN, Yang B, Yang SY, Chen YL, Zhao MM, Ashraf M, Jiang Y (2009). Identification of phenolic compounds and appraisal of antioxidant and antityrosinase activities from litchi (Litchi sinensis Sonn.) seeds. Food Chem. 116:1-7.

Saeed N, Khan MR, Shabbir M (2012). Antioxidant activity, total phenolic and total flavonoid contents of whole plant extracts Torilis leptophylla L. BMC Comp. Altern. Med. 12:221.

Saad B, Azaizeh H, Abu-Hijleh G, Said O (2006). Safety of traditional arab herbal medicine. Evid Based Compl. Altern. Med. 3:433-439.
Sahgal G, Ramanathan S, Sasidharan S, Mordi MN, Ismail S, Mansor SM (2010). Brine shrimp lethality and acute oral toxicity studies on Swietenia mahagoni (Linn.) Jacq. seed methanolic extract. Pharmacog. Res. 2(4):215-220.

Sen S, Chakraborty R, Sridhar C, Reddy YSR, De B (2010). Free radicals, antioxidants, diseases and phytomedicines: current status and future prospect. Int. J. Pharm. Sci. Rev. Res. 3(1):91-100.

Sumbul S, Ahmad MA, Asif M, Akhtar M, Saud I (2012). Physicochemical and phytochemical standardization of berries of Myrtus communis Linn. J. Pharm. Bioallied Sci. 4(4):322-326.

Sharma S, Vig AD (2013). Evaluation of In Vitro Antioxidant Properties of Methanol and Aqueous Extracts of Parkinsonia aculeata L. Leaves. The Sci. World J. Article ID 604865.

Sharififar F, Dehghn-Nudeh G, Mirtajaldini M (2009). Major flavonoids with antioxidant activity from Teucrium polium L. Food Chem. 112:885-888.

Todkar SS, Chavan VV, Kulkarni AS (2010). Screening of Secondary Metabolites and Anbacterial Activity of Acacia concinna. Res. J. Mcrobiol. 5(10):974-979.

Thamaraiselvi LP, Jayanthi P (2012). Preliminary studies on phytochemicals and antimicrobial activity of solvent extracts of Eichhornia crassipes (Mart.) Solms. Asian J. Plant Sci. Res. 2(2):115122.

Umamaheswari M, Chatterjee TK (2008). In vitro antioxidant activities of the fractions of Coccinnia grandis L. leaf extract. Afr. J. Trad. Compl. Altern. Med. 5:61-73.

Zaman R, Parvez M, Jakaria M, Islam M, Ali MS, Hossain MA (2016). In vitro antibacterial and antioxidant activities of alcoholic extract from the leaves of Podocarpus neriifolius D. Don. Afr. J. Pharm. Pharmacol. 10(37):791-795. 